\title{
Comparative Study of Poems in Chinese Textbooks of Primary Schools between China Mainland and Taiwan
}

\author{
A Case of Jiangsu Education Press and Nani Publishin g House \\ ${ }^{1}$ Qingqing Shen, ${ }^{2}$ Zuxiang Li \\ ${ }^{1}$ Education School, Nan Tong University Nan Tong University, Nan Tong, China \\ ${ }^{2}$ Education School, Nan Tong, China \\ 837681529@qq.com,lizuxiang@ntu.edu.cn
}

\begin{abstract}
Ancient Poem Teaching plays an important role in primary education. Chinese textbooks of primary schools published by Jiangsu Education Press from China Mainland and Nani Publishing House from Taiwan both included some poems. In number, there are 34 poems included in Jiangsu Education Press, while 6 in Nani Publishing House. On the subject, Jiangsu Education Press is about 7 themes and they're "keeping a record through scenery, caring the livelihood of people, expressing feelings according to something, patriotism, traditional culture, idyllic scenery and philosophy of life". While from Nani Publishing House, themes of expressing feelings according to something, keeping a record through scenery, anecdotes, idyllic scenery and philosophy of life are involved. In terms of the way of presentation, textbooks of two versions both have similarities and their own characteristics. Generally speaking, the Jiangsu edition can learn a lot from Nani edition, such as enriching poetry styles, adopting dynamic serial pictures, developing supplementary teaching materials and enriching extra classic reading, enriching the types of exercises.
\end{abstract}

Keywords: Chinese Textbooks, Primary Schools, Poems, Jiangsu Education Press, Nani Publishing House.

\section{INTRODUCTION}

Ancient poems is an important part of excellent Chinese traditional culture, and also plays a decisive role in Chinese textbooks. On March 26 $6^{\text {th }}$, 2014, the Ministry of Education issued "Perfecting Excellent Chinese Traditional Culture Education Guidelines", requiring "Putting excellent Chinese traditional culture into curriculum and teaching materials system" and "Strengthening excellent Chinese traditional culture in the course construction and curriculum standard revision". Against this background, the selection of poems in primary Chinese textbooks has increasingly attached more attention from the public. China Mainland and Taiwan have the same origin and share the same foundation of traditional culture. However, the inheritance of poems in primary school Chinese textbooks in both sides is totally different. Either of them has its own strong points.

\section{METHODS}

We choose primary school Chinese textbooks by Jiangsu Education Press in China Mainland and Nani Publishing House in Taiwan as analysis objects. We use comparative analysis approach to compare poetry and prose works in both sides from the aspect of distribution, contents and the way of presentation. 


\section{The Original and Teaching Values of Poems}

\subsection{The Original Value of Poems}

A poem is the wisdom of numerous scholars for thousands of years, as well as an important carrier of Chinese traditional culture. She's the most gorgeous annals, recording Chinese history and culture and inheriting Chinese classical civilization. She's the easiest teaching material, full of profound emotion, collecting the cadence of rhyme. She's the most beautiful movement, covering the whole world and moistening everything silently. In the long and winding history, she inherits historical civilization, cultivates children's linguistic sense and nurtures readers' spirituality. Generally, she has largely contributed to the ethnic and cultural inheritance. As a traditional literature form, poems' value can't be ignored.

\subsection{The Teaching Values of Poems in Primary School Chinese Textbooks}

Affection is real. As Moruo Guo (1920) says, "The essence of poems lies in expressing the emotion". And poems that recorded in primary school Chinese textbooks are filled with authors' various emotion."Time to pick lotus in Jiangnan and the lotus leaves become lush". From that, we can feel that the author loves the beauty of lotus and admires the diligence of laboring people."Beyond Gusu city, the bell from Hanshan temple comes into the passenger ship". From that, we can feel that the author can't control his homesickness because of the loneliness of living away from hometown, especially when he heard the bell."The cutest is the naughty little son, lying and taking the lotus seed out near the stream". From that, we can feel that the author yearns for the peaceful country life and is fond of the lovely kid."When the Song retook the lost ground, don't forget to tell your father the good news". From that, even if the author was sick in bed and seemed hopeless, the patriotic enthusiasm of defending his country didn't decrease.

As "Chuang Tzu- The World" (2009) goes, "Poems aim to show ambition". What the poems convey is the most sincere pursuit and emotion. No matter what it is for, the love of natural scenery, the admiration of laboring people, the attachment of hometown or the pursuit of lofty sentiments, all of them are poets' real emotional appeal in the depth of their heart. It's only the real feelings that bring today's children true affective experience. And that's why it's still immortal through thousands of years.

The scenery is beautiful. Most poems in primary school textbooks are related to the depiction of scenery. They may show pretty rural scenery, such as "Near the small reed-thatched house, there is a clean stream, surrounded by rich green grass ". Or they may describe splendid natural scene, such as "The sunset is sinking with the mountain, the Yellow River is flowing towards the East Sea". Not only the scenes of life but also the scenes of nature are vivid and moving. The space of one's life is always limited, but gorgeous ancient poems can present numerous fabulous situation and enrich children's aesthetic experience. Their life is not just surrounded by high buildings, instead, they can feel the sugar bush from "The frost-dyed maple leaves are better than bright flowers in February", the villages from "There are several pavilions, terraces and open halls", the pond from "Tier upon tier of lotus leaves seem to extend to the distant sky, with our eyes full of green" and the surprise from "An apricot flower extends out over the fences". Their life experience is not just the sound of loud reading, besides, they can feel the pity from "Every grain comes from hard working", the excitement from "Outside the Jianmenguan, we got the news that they had recaptured the lost ground", the peace from "The accent of $\mathrm{Wu}$ area sounds very soft and nice" and the regret from "The clouds are too thick to distinguish directions". 
The truth is perfect. As Dunyi Zhou, a philosopher of Neo-Confucianism in the Song Dynasty, says, "The article is the carrier of truth, and just like the vehicle as people. If the vehicle doesn't carry people, there's no use decorating the wheel and the handle perfectly". He pointed out that "article" is like "vehicle" and "truth" is like "goods", and goods can get to the destination only with the help of the vehicle. In other words, literature is the means and tool to diffuse Confucianism. Confucianism started from pre-Qin period, set up by Confucius, developed by Mencius and Xuncius, enriched by Zhongshu Dong and Xi Zhu, and finally seen as a huge authentic cultural system by rulers of all dynasties since the Han Dynasty. Confucian culture is the important content through Chinese history, as well as the core part of Chinese national culture. Even the poems existing in Chinese textbooks contain excellent Confucian culture. For instance, the political ideology in "Benevolence", the traditional morality in "Humanity, justice, propriety and wisdom", the learning attitudes in "Learning insatiably", and so on. All of these classical and nice Confucian are of great significance for Children's character formation.

\section{RESULTS AND DISCUSSION}

\subsection{Comparison of Distribution}

There are 284 lessons in primary school Chinese textbooks by Jiangsu Education Press, and 298 works are included. From Table 1, we can find there are 34 poetry and prose works, 31 poems and $3 \mathrm{Ci}$ included , accounting for $11.4 \%$ of text-selection system of the full textbook.

There are 168 lessons in primary school Chinese textbooks by Nani Publishing House, and 169 works are included. Among them, there are 6 poetry and prose works, 3 poems, 2 short stories and $1 \mathrm{Ci}$ included , accounting for $3.56 \%$ of text-selection system of the full textbook.

On the whole, Jiangsu Education Press has a greater proportion of poems in the textbook than Nani Publishing House. It's not difficult to conclude that China Mainland attaches more attention to the inheritance of excellent traditional culture than Taiwan in Chinese textbook compilation.

Table1.The Number of Poetry and Prose Works in Different Grades

\begin{tabular}{|c|c|c|c|c|c|c|}
\hline & \multicolumn{3}{|c|}{ Jiangsu Education Press } & \multicolumn{3}{|c|}{ Nani Publishing House } \\
\hline & \multirow[t]{2}{*}{$\begin{array}{l}\text { The Number of } \\
\text { Selected Articles }\end{array}$} & \multicolumn{2}{|c|}{$\begin{array}{c}\text { The Number of Poetry } \\
\text { and Prose Works }\end{array}$} & \multirow[t]{2}{*}{$\begin{array}{l}\text { The Number of } \\
\text { Selected Articles }\end{array}$} & \multicolumn{2}{|c|}{$\begin{array}{c}\text { The Number of Poetry } \\
\text { and Prose Works }\end{array}$} \\
\hline & & Number & Share & & Number & Share \\
\hline Grade 1 & 40 & 4 & $10 \%$ & 28 & & \\
\hline Grade 2 & 48 & 3 & $6.25 \%$ & 28 & & \\
\hline Grade 3 & 51 & 4 & $7.84 \%$ & 28 & & \\
\hline Grade 4 & 51 & 8 & $15.69 \%$ & 28 & & \\
\hline Grade 5 & 55 & 7 & $12.73 \%$ & 29 & 2 & $6.90 \%$ \\
\hline Grade 6 & 53 & 8 & $15.09 \%$ & 28 & 4 & $14.29 \%$ \\
\hline Total & 298 & 34 & $11.40 \%$ & 169 & 6 & $3.56 \%$ \\
\hline
\end{tabular}

What's more, we can find some distribution rules between these textbooks of two versions. In the version of Jiangsu Education Press, the number of poetry and prose works of Grade 1, 2 or 3 is bout 3 or 4 and starts to increase since Grade 4.In Grade 4, 5 or 6, there are almost 7 or 8 works. Grade 4 and 6 record the most poetry and prose works, and also account for the largest percentage of selected texts. Grade 4 has recorded 8, accounting for $15.69 \%$ of selected texts. Grade 6 has recorded 8, accounting for $15.09 \%$ of selected texts. Generally, the number and proportion have showed progressive tendency with the development of periods. Among these 34 poems, there are about 20 poems from the Tang Dynasty, and the Song Dynasty takes the second place, 10. And there is only one separately from the Yuan, Ming 
and Qing dynasties. Overall, the number of poetry and prose works is well-distributed and increases gradually with periods. In addition, the poems are from various dynasties, which can make students get in touch with all kinds of masterpieces and have an overall impression of our ancient poem development.

The arrangement of that is in accordance with the primary school Chinese curriculum objectives of New National Curriculum Standard in Mainland. That is, during the first stage, students should be able to read and recite children's songs, children's poems and simple ancient poetry so that they can require preliminary emotional experience and feel the beauty of language. Besides, they must recite 50 excellent poems (sections).During the second stage, students should be able to read and recite beautiful poems and feel the emotion, use the imagination, understand the meaning. Besides, they must recite 50 excellent poems (sections).During the third stage, students should be able to read poetry, grasp the general meaning, imagine the situation that the poetry describe and feel the author's affection. Also, they should pay attention to the tone and rhythm when feeling the poem. Besides, they must recite 60 excellent poems (sections).

In Nani Publishing House, the lower and middle grade in primary school don't record any poetry and prose works until Grade 5.There are 2 in Grade 5,accounting for $6.9 \%$ of selected texts in this grade. And there are 4 in Grade 6, accounting for $14.29 \%$.If we just look from the sheer numbers, the number of poems in that set of textbooks in Grade 6 is twice of that in Grade 5.Among these 6 poems, there are about 3 poems from the Song Dynasty, accounting for 50\%.And the Tang Dynasty takes the second place, 2. While there is only one from the Qing Dynasty. Though Nani Publishing House doesn't record enough poetry and prose works, we can't deny the novelty of classical Chinese short story, which is the specific semantic coherent classical Chinese works in ancient China. And they're closer to the life, the masses. Reading classical Chinese novels can increase students' ancient literature knowledge, build up their language sense, and lay the foundation for their next middle school career.

It seems strange that there's no poetry and prose works during the lower and middle stage while the number increases suddenly during the high stage in Nani Publishing House. It is reasonable actually. According to the reading requirements of the third stage from Grade 1-9 Curriculum Guidelines in Taiwan, students should be able to know works with different styles and themes and broaden the reading range. According to the key point of the overall curriculum implementation in Taiwan, students should incorporate themselves into classical Chinese during the third stage. And relevant departments should adapt the share of classical Chinese year by year during the fourth stage $\left(10 \%--20 \%\right.$ in the $7^{\text {th }}$ term, $20 \%--30 \%$ in the $8^{\text {th }}$ term, $25 \%--35 \%$ in the $9^{\text {th }}$ term).

In conclusion, the distribution of poems in the textbooks of two versions is quite different because of the different curriculum documents in China Mainland and Taiwan.

\subsection{Comparison of Contents}

Table2. The Number of Poetry and Prose Works in Different Themes

\begin{tabular}{|l|c|c|c|c|}
\hline \multirow{2}{*}{} & \multicolumn{2}{|c|}{ The Jiangsu Education Press } & \multicolumn{2}{|c|}{ Nani Publishing House } \\
\cline { 2 - 5 } & Number & Share & Number & Share \\
\hline 1.keeping a record through scenery & 18 & $52.94 \%$ & 1 & $16.67 \%$ \\
\hline 2.caringthe livelihood of people & 2 & $5.89 \%$ & 0 & $0.00 \%$ \\
\hline $\begin{array}{l}\text { 3.expressing feelings according to } \\
\text { something }\end{array}$ & 3 & $8.82 \%$ & 2 & $33.33 \%$ \\
\hline 4.patriotism & 5 & $14.71 \%$ & 0 & $0.00 \%$ \\
\hline 5.traditional culture & 1 & $2.94 \%$ & 0 & $0.00 \%$ \\
\hline 6.idyllic scenery & 3 & $8.82 \%$ & 1 & $16.67 \%$ \\
\hline
\end{tabular}


Comparative Study of Poems in Chinese Textbooks of Primary Schools between China Mainland and Taiwan

\begin{tabular}{|l|c|c|c|c|}
\hline \hline 7.philosophy of life & 2 & $5.89 \%$ & 1 & $16.67 \%$ \\
\hline 8.anecdotes & 0 & $0.00 \%$ & 1 & $16.67 \%$ \\
\hline Total & 34 & - & 6 & - \\
\hline
\end{tabular}

34 poetry and prose works in textbooks by Jiangsu Education Press can be concluded into the following themes. They are keeping a record through scenery, caring the livelihood of people, expressing feelings according to something, patriotism, traditional culture, idyllic scenery and philosophy of life.

As Table 2 shows, the theme of keeping a record through scenery accounts for the largest proportion, about $52.9 \%$ of all poetry and prose works. The theme of patriotism takes the second place, about $14.71 \%$. The share of traditional culture is the least, about $2.94 \%$. Why does the primary school Chinese textbooks by Jiangsu Education Press focus on the theme of keeping a record through scenery? That's because the works of this theme can present the scene and the thing with simple words, describing the wonderful scenery and narrating the complete events. So, it's easy to read, experience, feel, even put into practice, which conform to students' cognition degree and learning interest. For example, "On the Pond", "The Little Son is Fishing", "A View of the Lush an Waterfall", "The Seen", and so on. From "On the Pond", we can feel the naughty in the verse "The kid is boating with an oar". From "The Little Son is Fishing", we can feel the loveliness in "The naive kid with floppy hair is learning to fish". From "A View of the Lush an Waterfall", we can feel the magnificence in "The waterfall flies straight down in a rush". From "The Seen", we can truly feel the shepherd's happiness in "The sound echoed through the street". Poems like such types are full of strong smack of life and sense of pictures, which are suitable for students to read, and also adjust to children's aesthetic demands.

What's more, the selection of themes in Jiangsu Education Press has its own characteristic. The theme of poetry and prose works from Gade1 to Grade 5 focuses on keeping a record through scenery. When students come to the cohesion stage--Grade6, themes become richer and richer, like patriotism, philosophy of life, keeping a record through scenery, idyllic scenery and expressing feelings according to something, which almost include all types of themes through the whole textbook system. Thus, we can predict boldly that such abundant poetry themes is a recognition of students' cognition abilities in Grade 6.According to Piaget's Cognitive Development Theory, firstly, the cognition ability of students in Grade 6 has reached the formal operation stage and students have enough ability to separate form from content, to tell the difference among different themes of the same style correctly. Secondly, such rich poetry themes can make students learn about the diversity of Chinese classical poems and accumulate more language knowledge, which are beneficial for their middle school language learning.

6 poetry and prose works in textbooks by Nani Publishing House can be concluded into the following themes. They are expressing feelings according to something, keeping a record through scenery, anecdotes, idyllic scenery and philosophy of life. Among them,2 are about expressing feelings according to something and they're both in Grade 5. While other 4 themes are all in Grade 6 and each theme has one work. Similarly, the richness of the theme in Grade 6 by Nani Publishing House and the arrangement of the theme by Jiangsu Education Press just have the different approaches but equally satisfactory results.

All poetry and prose works recorded by these two versions have similar characteristic. From the aspect of the tone, "The beauty of classical poetry mostly comes from tonal harmonious". Because of the transformation of "level and oblique tones" and "four tones", the poems then can be read rhythmically. Let's take "On the Stork Tower" as an example. 


\section{Qingqing Shen \& Zuxiang Li}

On the Stork Tower

Tang Zhihuan Wang

The sunset is sinking with the mountain,

The Yellow River is flowing towards the East Sea.

For a view a thousand miles away,

Taking another step forward.

Entering, entering, level, level, falling,

Level, level, entering, falling-rising, level.

Falling, level, level, falling-rising, entering,

Falling, falling-rising, entering, level, level.

[Four tones]

Oblique, oblique, level, level, oblique,

Level, level, oblique, oblique, level.

Oblique, level, level, oblique, oblique,

Oblique, oblique, oblique, level, level.

[Level and oblique tones]

From the aspect of the rhetoric "antithesis", we can find that two consecutive lines of poems are always perfect in symmetry and words are in perfect harmony too. For instance, from "In the willows two orioles are singing, in the sky egrets are flying" in "Four Lines" in the textbook of the second volume of Grade 3 in Jiangsu Education Press, we can feel the line is so clear and the content are against each other appropriately. From the aspect of rhyme, putting Chinese words with the same vowels at the terminal of each sentence can make poems sound catchy, full of musical beauty. Let's take "The Eagle", from the first volume of Grade 5 in Nani Publishing House, as an example.

The Eagle[1]

Tang Bai Li

Cool in August in Northern Xinjiang,

Eagles are wearing white feather.

Looking like a huge snow floating,

Yet perceive everything a hundred miles away.

Cold in December, the eagle got arrested,

Powerful feathers are cut by hunters.

Little swallows and sparrows speak noisily, laugh out loudly,

Eagle swear to fly in the sky strugglingly.

The last word of each line pronounce "Gao", "Mao", "Hao", "Gao", "Zhao" in Chinese, which have the same rhyme "ao" so that students can read smoothly, remember easily. Thus, they satisfy not only the requirement of literature but also aesthetics. That's why these 39 poems can be selected into primary school textbooks. What's more, they conform to the three-dimensional objectives, Chinese teaching 
knowledge and ability, process and method, emotional attitude and values.

Except these similarities, these two versions have the same poetry and prose works. They both recorded the Song $\mathrm{Ci}$, "Peaceful Life in the Village" and see it as the illuminative work of Ci. The author used "thatched roof", "the stream", "the grass" to set a background, and then described "the old couple", "the eldest son", "the second son", "the youngest son", and so on. The author got the scenery, the people, the thing, the emotion all together and showed us a peaceful and comfortable rural life with brisk and smooth language, making people indulge in it deeply.

From Grade 1 to 4,poems is the only style of recorded poetry and prose works in Jiangsu Education Press. The Ci ,"Peaceful Life in the Village", exists in the first volume of Grade 5.In Nani Publishing House, students in Grade 5 and the first term of Grade 6 only learn poems. And "Peaceful Life in the Village" exists in the second term of Grade 6.Textbooks of these two versions both make students learn the $\mathrm{Ci}$ in high grade. Students at this stage have a full understanding of basic classical Chinese works--poems, while the $\mathrm{Ci}$ is evolved from poems. The arrangement from simple to complex can make students learn $\mathrm{Ci}$ on the basis of poem learning, which conforms to the historical context of ancient literature development and students' cognitive characteristic from easy to difficult. Besides, "Peaceful Life in the Village" is a good choice to let students get in touch with a new style of poetry and prose works. From the aspect of the style, the $\mathrm{Ci}$ is a typical family narrative work, we can find that words and scene combined with life like "thatched roof", "the grass", "weeding", "naughty" can remind students of their life experience, arose their visual and sensory experience. From the aspect of the content, the $\mathrm{Ci}$ uses the technique of "Low first and then high" and describes a lovely child with huge efforts, bringing students multiple experience and feelings like sentiment, beauty, truth, interestingness. This method can also cater to pupil's aesthetic taste and reading anticipation. From the aspect of the theme, Qiji Xin didn't write traditional family narrative poems that are full of flashy content ,but turned to describe leisurely idyllic life. He chose the scene, "The eldest son is farming very hard", "The second son is helping him" and "The youngest son is so innocent" to present harmonious family ethical relationships, which is a hint of morality and reason for children. From the aspect of the length, each sentence has 4-7 words in this Ci, similar to "Four line poems" and "Eight line poems". Besides, the content of each sentence always focuses on one thing or one scene and the form is compact but highly corresponds to the theme. That's helpful for pupils to learn $\mathrm{Ci}$ on the basis of poem learning. From the aspect of the rhyme, the first four sentences of the Ci have the same rhyme "ao", and the last four sentences have the same rhyme "ong" "eng". That makes them easy to read. In the past dynasties, poetry and prose works once are sang with the music, whose beautiful rhyme and musical words can make pupils recite easily and accept aesthetics invisibly. A plain $\mathrm{Ci}$ is not only easy to understand, but also pay attention to the teaching values of knowledge, emotion, meaning, and so on. There's no doubt that both versions have recorded this $\mathrm{Ci}$ and consider it as a start of ancient $\mathrm{Ci}$ learning.

\subsection{Comparison of the Way of Presentation}

Poetry and prose works in textbooks by Jiangsu Education Press consist of 5 parts. They are the poem, the author, new words, exercises and illustrations. The poems usually take one page, located in the middle of the page, brief and focused. The author is located in the lower left, as a note. New words and excises are on another page. New words are written in Arial Black in the middle of matts, serving as an example. Exercises come after the new words, including reading and reciting, tracing, word exercises and describing poetic conceptions. Only in this way can students consolidate the work timely. Illustrations are usually located below or on the opposite page, taking the whole page. Most of them are claborate-style paintings. Both the characters and the scenes are vivid, which are useful for pupils to 
understand the poetry and prose works.

Poetry and prose works in textbooks by Nani Publishing House consist of 6 parts. They are the poem, the author, new words, the notes, the analyses and illustrations. The poems usually take 1-3 pages and the lines are well-arranged that look comfortable. The author is located below the headline, which is obvious and arresting. New words of each page are located below. They are usually written in the small square with the black font and red character components. The analyses and illustrations are located 2-3 pages after the poem. Illustrations often locate below the poem, notes and analyses, using claborate-style paintings too but in the way of serial pictures. These pictures develop with the plot of poems and can stimulate students' learning interest.

There are some similarities between the two versions. From the aspect of the content, they both have 4 parts, the poem, the author, new words and illustrations, which satisfy the teaching objectives in literacy, reading, material accumulation and aesthetics. From the aspect of the form, the font of the poem and new words are regular script. New words are written in the small square standardly, which satisfy the objectives in literacy and writing imitation. Both two versions have illustrations to explain the poem, help students know the poem better and learn better.

There are also some differences between the two versions. From the aspect of the content, there are notes and analyses in textbooks by Nani Publishing House while there aren't in that by Jiangsu Education Press. From the aspect of the form, new words exist twice in textbooks by Jiangsu Education Press. The first time is the summary after the poem and the second time is the cuisive writing in exercises part, which emphasize literacy and writing training. While the version of Nani Publishing House doesn't arrange matched literacy exercise and only has one summary. In addition, Jiangsu Education Press has corresponding exercises to consolidate what pupils learned timely, while Nani Publishing House doesn't. And the concrete form of illustrations of two versions is totally different too.

In the textbooks by Jiangsu Education Press, illustrations of poems are usually static pictures, trying to create a situation to help pupils understand the meaning of poems. For instance, we can see a picture that the falling raindrops are moistening the flowers in spring in "Spring Rain", pretty people open the window and enjoy the song of birds and the sweet smell of flowers in "A Spring Morning", the poet is overlooking on the stork tower in "On the Stork Tower" and the poet is watching the waterfall flying straight down in a rush in "A View of the Lushan Waterfall". In the textbooks by Nani Publishing House, illustrations of poems are usually dynamic pictures and develop with the plot. For example, we can see the whole story in "A Trick" through pictures of "show the empty bucket", "put the rice on the mat", "pour the rice in the bucket", "show the empty bucket again", and so on. We can see the whole scenery in "Peaceful Life in the village" through pictures of "the grass are near the stream", "people are working hard" " the naughty little son is lying and taking the lotus seed out ".In this way, students can understand the poem and recite it easily. Thus, when it comes to the teaching effect, dynamic serial pictures are better than static pictures.

\section{CONCLUSION}

\subsection{Enriching Poetry Styles in Jiangsu Education Press}

There are only poems and $\mathrm{Ci}$ in textbooks by Jiangsu Education Press. It's not enough for current students who may have been learning poetry and prose works since Grade 1 or even kindergarten period. That is to say, what pupils need far exceeds what we provide. Chinese classical novels, the treasure of 
our traditional literature, having experienced cultural inheritance, historical evolution and accumulation, has its own teaching values and should be eternally renewed. However, it's a pity that textbooks by Jiangsu Education Press don't record Chinese classical novels and their value and effect seem to be ignored.

As far as I'm concerned, the inspiration of enriching the styles of selected texts in primary school Chinese textbooks by Jiangsu Education Press comes from Nani Publishing House. Besides, there are some other reasons as follows. Firstly, pupils' abilities of learning and reciting are powerful and what they have recited in their childhood will be impressive for life."If students don't learn and recite more abundant traditional classical works at a period with good memory, there will be a waste of vigor and pity of life. They are capable of accepting relatively shallow Chinese classical novels."A vice-president in Nantong Chenzhong Primary School, Hongjuan Shen (2012) said. Secondly, poetry and prose education is becoming a fashion. It's common that many kids have learned some poetry and prose works before they enter primary schools. Therefore, they need wider and broader knowledge to satisfy their curiosity instead of repetitive content. Finally, Chinese classical novels have their unique literary position and require students to learn. Literature has been possessed only by the intellectual since ancient times. Thanks to the appearance and development of Chinese classical novels, they make culture be closer to the public. Their language is plain and easy to read, and close to life. In addition, they present us a full view of the ancient society and provide massive resources for students' comprehensive culture literacy education. Adding more styles of poetry and prose works can not only enrich the style in textbooks, but also cultivate students' taste and promote their intellectual development.

\subsection{Adopting Dynamic Serial Pictures}

Illustrations of poetry and prose works by Jiangsu Education Press are always one static picture. Let's take "A Poem Written in Wanghu Building after Drinking in June 27th" as an example. The illustration of this poem is that a poet is standing sideways on the little boat in the river, which actually conforms to the situation at that time. However, the only one picture can't reflect the whole view and variations. In fact, the meaning of the poem is as follows. "Black clouds get together like the ink spill out suddenly. Yet a mountain appears surprisingly, bright and fresh. The water splash everywhere as pearls jump into the boat. The winds comes again, sweeping the dark clouds away. The lake now is so clear like a mirror, beautiful and gentle". Four sentences of this poem describe a series of dynamic scenery, and show us the natural rainy and sunny scenes. How can a static picture express such scenery?

Comparatively, illustrations by Nani Publishing House are more appropriate and elaborate. Let's take "A Guest is Coming" as an example. The first illustration is that "The guest is just outside the door ".The second is that "The poet opens the door and greets the guests". The third one is that "They sit and drink opposite each other comfortably". A complete story is vivid in front of us and sequential situation can be remembered by students quickly.

Generally, a set of serial and dynamic pictures can satisfy the development of plots and fill in the blanks of contents, making the significance of poetry and prose works more intuitional and lowering the difficulty of learning. Besides, transforming words into pictures can let students grasp the meaning of poems during the process of reading pictures and motivate their learning enthusiasm. 


\subsection{Developing Supplementary Teaching Materials, Enriching Extra Classic Reading}

The classics is worthy of inheriting. Poetry and prose works is an important part of Chinese classical literature, reflecting the wisdom and creation of the masses. It can also express sincere emotion and diffuse traditional morality. As a literary form, it can bring people unique aesthetic experience. The beauty of the language, the emotion, the rhyme and the situation has a great value of appreciation and education.

In Taiwan, each regional government has their own Chinese supplementary teaching materials except for textbooks. Let's take "National Primary School Chinese Supplementary Teaching Materials in Taibei" as an example. There are 6 volumes (186 selected texts) in supplementary materials, all of which are poetry and prose works. There are 150 ancient poems in them, accounting for $80.6 \%$ of all selected texts. Developing supplementary materials of poems and arranging the sequence of classical works scientifically can enrich students' learning resources. What's more, students have another chance to read, recite and accumulate Chinese traditional poems and gain their own experience of traditional language culture.

\subsection{Enriching the Types of Exercises in Jiangsu Education Press}

Exercises in Jiangsu Education Press is a significant approach for students to consolidate what they have learned. But the type of that is too monotonous. There are mainly 4 types, reading and reciting, tracing, word exercises and describing poetic conceptions. Among them, exercises for Literacy Teaching are tracing and word exercises. Exercises for Teaching of Reading are reading and reciting and describing poetic conceptions. All these exercises use the form of task instructions or questions. For example, "Read and recite the poem", "What do you see after reading these two poems?". They aim to keep students accumulating Chinese language.

A Chinese teacher in Grade 6 from Gaoxiong, Taiwan, said, their quizzes usually adopt electronic databases in class and that's why they don't have exercises in textbooks. She introduced their practice forms as follows. "There are thousands of quizzes in the electronic databases. We have 20 more forms, like Error Correction, Choice Questions. Besides, we renew the quizzes every year. Sometimes we let students act out the text and make into a MV on the Face book".

So why don't we adopt more interesting exercises to help students consolidate their knowledge? We can add some questions such as riddles, brainteasers, situational applications, continuing a story. From those types of exercises, students can accumulate more abundant knowledge, try to imagine, or begin to use poems in life. Let's take "situational applications" as an example."A View of the Lushan Waterfall" is a poem in the second volume of Grade 3 by Jiangsu Education Press, whose quizzes are as follows. Firstly, "Read and recite the poem". Secondly, "Trace with the pen". Thirdly, "Explain the meaning of marked words". Next," Choose one poem to use your own words to describe the scenery". Finally, "Do you know any other poems that describe famous mountains and rivers in China? Recite one or two with your partners". However, if we add a question like this, "The waterfall is flying straight down in front of me. The water is splashing everywhere, clear and beautiful. I can't wait to scoop up some and feel cool. Such wonderful scenery make me think of the poem named 'A View of the Lushan Waterfall',

".What's the difference between the old questions and the new one? Quizzes designed as that can not only deepen students' understanding of poems and teach them how to use poems in real life, but also strengthen their interest of learning poems and make knowledge repetition funnier. 


\section{REFERENCES}

[1] Bo Yu.2010.Poem Teaching and Confucian Culture. Liaoning: Liaoning Normal University,1 5.

[2] The Ministry of Education of the People's Republic of China. Chinese Curriculum Standards of Compulsory Education.2011.Beijing: Beijing Normal University Press, 8-13.

[3] The Ministry of Education (Taiwan).1997.National Primary and Secondary School Grade 1-9 Curriculum Guidelines (Chinese).http://www.k12ea.gov.tw/ap/sid17_law.aspx.

[4] Tuiyuan Qu,Ziyi Zhou. About Poems.2014.Beijing: Contemporary China Publishing House.

\section{AUTHORS'BIOGRAPHY}

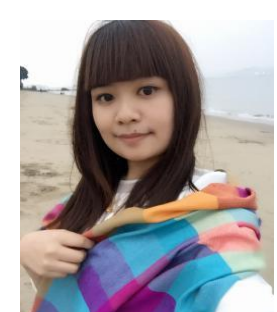

Qingqing Shen, is a graduate student in Nan Tong University majoring in Curriculum and Teaching Methodology. She has been doing projects related to curriculum research with her tutor for more than three years and attended many academic conferences, like "The $3{ }^{\text {rd }}$ Summit Forum for Textbook Studies in the Four Regions Across the Straight" held in Beijing on March $8^{\text {th }}, 2015$,"The $9^{\text {th }}$ National Curriculum Academic Seminar" held in Shanghai on November 1" ${ }^{\text {st }}$, 2014and "The $7^{\text {th }}$ International Conference on ELT in China" held in Shanghai on October $24^{\text {th }}, 2014$.

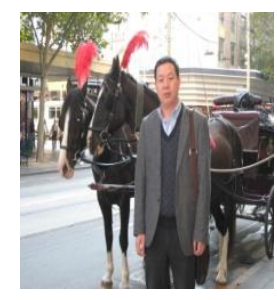

Zuxiang Li, is a professor of education in Nan Tong University, who devotes himself to textbooks research of primary school .He has published more than 300 articles and 2 books, and taken part in 4 national and provincial research projects, which make him famous in curriculum field. 